This is a postprint/accepted version of the following published document:

Brown, O.; Paz-Aparicio, C.; Revilla, Antonio J. Leader's communication style, LMX and organizational commitment: a study of employee perceptions in Peru. In: Leadership \& organization development journal, 40(2), April 2019, Pp. 230-258.

DOI: https://doi.org/10.1108/LODJ-03-2018-0129

(C) Emerald Publishing Limited 


\title{
Leader's communication style, LMX and organizational commitment
}

\section{A study of employee perceptions in Peru}

\author{
Ofelia Brown \\ Department of Management, Universidad ESAN, Lima, Peru \\ Carmen Paz-Aparicio \\ Institute of Entrepreneurship and Family Business, \\ Universidad Carlos III de Madrid, Madrid, Spain, and \\ Antonio J. Revilla \\ Bath Business School, Bath Spa University, Bath, UK
}

\begin{abstract}
Purpose - The purpose of this paper is to analyse the impact of a leader's communication style (LCS) on the quality of interpersonal exchanges between leaders and followers (LMX), and how this translates into the employee's affective organizational commitment (AOC), in the context of Peru.

Design/methodology/approach - An integrated model of six dimensions is used to measure LCS. Using multiple hierarchical regressions and the Preacher and Hayes mediation model, the study focuses on determining the direct and indirect effect of each of the dimensions on LMX and organizational commitment.

Findings - The dimension preciseness shows a significant direct association to AOC. Four dimensions are significantly related with LMX: expressiveness, preciseness and questioningness with a positive sign, while verbal aggressiveness records an important negative one. The same four dimensions show an indirect effect on AOC through LMX. Emotionality and impression manipulativeness do not record significant results.

Research limitations/implications - The research was carried out with a sample of 253 white-collar Peruvian professionals with high-level studies and managerial experience, which are not necessarily representative of the labor population. This research provides comprehensive evidence on how leaders' communicative behavior may contribute to desirable outcomes such as employee commitment in a Latin American cultural context, although the findings may apply to other cultures.

Practical implications - This study contributes to clarify that each dimension of the LCS impacts differently on subordinate perceptions; leaders should understand this model and be able to make the necessary adjustments to their communication in order to obtain the desired results of leadership. The leader's ability to communicate with a style characterized by expressiveness, precision, and questioning makes it easy to build high-quality LMX relationships for Peruvian employees. On the contrary, a communication style characterized by high levels of verbal aggressiveness may negatively affect subordinates, limiting the possibility of building high-quality LMX relationships. This, in turn, affects AOC of employees.

Social implications - This study is a contribution to clarify that each feature of the LCS has a different impact on the perception of the subordinate, for which the leaders should be trained to understand this model and be able to make the necessary adjustments to obtain the desired results of leadership. The leader's ability to communicate with a style characterized by expressiveness, precision and questioning makes it easy to build high-quality LMX relationships for Peruvian employees. On the contrary, a communication style characterized by high levels of verbal aggressiveness will negatively impact subordinates, limiting the possibility of building high-quality LMX relationships.

Originality/value - The value lies in revisiting the construct "leader's communication style" to turn it into an instrument for the exercise of leadership. It is a contribution in favor of leaders becoming aware that their own communication style constitutes an instrument of effective leadership and a lever to optimize the commitment of their collaborators toward the organization.
\end{abstract}

Keywords Peru, National culture, Leader-member exchange (LMX), Affective organizational commitment, Organizational communication, Leader's communication style

Paper type Research paper

Received 30 March 2018 Revised 27 August 2018 26 October 2018

21 December 2018 Accepted 4 January 2019 


\section{Introduction}

Although the benefits of communication for organizations have been studied for decades, the line of research on the components of the leader's communication style (LCS) and their effects remains, comparatively, underdeveloped. Leaders are often not aware of their communication and do not give importance to it, so they do not realize that the way they communicate is perceived by their subordinates as their way of leading. In line with this, communication often seems so obvious and so embedded in human interactions that are hard to perceive. Fairhurst (2011, p. 43) quotes a story by David Foster Wallace in order to explain the nature of communication: "Two young fish are swimming along, and they pass an older fish swimming the other way. The older fish nods at them and says, Morning, boys. How's the water?" As the two young fishes swim on, one eventually turns to the other and says, "What the hell is water?" The attitude of the young fish could be predicated of many leaders who consider communication occurs naturally and are not aware of the impact the way they communicate has on their subordinates and on management outcomes (Fairhurst, 2011).

The studies of Norton (Norton, 1978; Norton and Miller, 1975) in the 1970s, those of Gudykunst in the field of communication style in intercultural contexts (Gudykunst et al., 1987; Hammer et al., 1978) and those of de Vries et al., in The Netherlands from the field of psychology (de Vries et al., 2011; de Vries et al., 2010; de Vries et al., 2009) are some attempts to propose integrated models to understand how the combination of traits results in a personal style of communication. Communication is a complex and multidimensional construct. An LCS can be understood as the set of communicative behaviors that a supervisor uses during interpersonal interactions geared toward the optimization of hierarchical relationships in order to reach goals. The combination of its dimensions (expressiveness, preciseness, verbal aggressiveness, questioningness, emotionality and impression manipulativeness) makes up a particular and personal style of leadership communication (de Vries et al., 2011) and may influence management outcomes.

The relationship between communication and leadership continues to merit attention in the literature for some reasons. On the one hand, previous research has shown repeatedly and clearly, the crucial role that communication plays in management (Christensen and Cornelissen, 2011; Taylor, 2011). On the other hand, but in the same line, times change and so do human relationships. The increasing use of information technologies (Tapscott, 2015), the tendency of more horizontal and less vertical organizations, and new management and leadership models have contributed to shape employee expectations regarding the role of leaders (Drucker, 1988). In this context, communication becomes more participative and less authoritarian, meaning centered, relational and geared toward support and coaching (Fairhurst and Connaughton, 2014). Managers can see their leadership challenged if they fail to meet follower expectations in a context of change in interpersonal relationships (Sniderman et al., 2016).

From this perspective, communication is an instrument that leaders can use to build healthy and productive relationships with their subordinates. According to leader-member exchange (LMX) theory (Graen and Uhl-Bien, 1995), leadership is a relationship between two individuals, generated over the course of their daily interactions in their roles of supervisor and subordinate. These exchanges can be seen as communicative acts - instructions, orders, explanations, inquiries, reports, coordination, motivational messages and vision sharing, among others. Inspirational communication (Rafferty and Griffin, 2004), transformational leadership (Meyer et al., 2002) and LMX (Wayne et al., 2002) can foster an employee's affective commitment, which, in turn, can trigger desirable outcomes, such as reduced turnover, absenteeism, higher job performance, and organizational citizenship behaviors (Meyer et al., 2002).

Additionally, previous research on LCS has been essentially circumscribed to a western European and North American setting. De Vries et al. (2011) developed and tested their 
multidimensional model on a Dutch sample. However, leadership literature, most notably the GLOBE study (House et al., 2004), has established that conceptualizations of leadership, desirable leader traits and organizational outcomes vary across national and regional cultures. There is a long-standing debate in the literature between competing propositions regarding the universalistic vs culture-contingent elements of effective leadership (e.g. House et al., 1997; Hamlin, 2004; House et al., 2004; Holten et al., 2018).

The main contributions our study makes to existing literature can be summarized as follows: first, it provides evidence on the consequences of LCS using and validating a multidimensional model of communication, therefore helping leaders comprehend how their communicative behaviors affect member perceptions and contribute to their leadership. This research reasserts the importance of a comprehensive and complex model of communication styles and its contribution to leadership research. Second, this study integrates recent developments in the literature on LCS - particularly the communication styles inventory (CSI) proposed by De Vries et al. (2011) - and integrates it with LMX theory in order to extend previous literature and gain a better understanding of the mediated causal relationship between the different dimensions of LCS and affective organizational commitment (AOC). In so doing, we claim that the effectiveness of communication largely depends on whether communicative behaviors help leaders develop high-quality relationships with their followers. In summary, we pose the following research question:

$R Q 1$. How does LMX mediate the relationship between the different dimensions of leader communication styles (LCS) and employee affective commitment to the organization?

From an empirical perspective, this study analyses the perceptions of a sample of Peruvian professionals in order to evaluate LCS, unlike previous research on this area, which had overwhelmingly focused on North America and Western Europe. We take concepts and relationships that have been developed within developed countries with horizontal-individualistic cultures and evaluate them in a different cultural and socioeconomic setting. Accordingly, this paper aims to address a second research question:

RQ2. What are the effects of the different dimensions of an LCS on LMX and subsequently AOC of employees in a Latin American country with an emerging economy, such as Peru?

This paper outlines how these effects may differ from what previous research has found in different cultural contexts.

Ultimately, this paper aims to contribute to a better theoretical and empirical understanding of the joint role that leader communication and LMX play in linking leadership theory and effective leadership practises, considering the cultural setting in which leadership develops.

The rest of the paper is organized as follows: We first set out the theoretical framework used to test our hypotheses and explain our contribution. We then describe the data, the variables and the empirical method used. The following section describes the main results. Finally, we discuss the main findings and describe the study's contributions and implications, its limitations, and topics for future research.

\section{Background}

\section{The communicative behaviors of leaders}

Communication creates and integrates organizations through a network of interrelations and information sharing, coordination, control, and management. Communication integrates levels - individual, group, organization - so that the organization is gradually constituted by its goal-oriented actions (Phillips et al., 2004). In these processes, leadership communication plays a crucial role, given that leaders explain efforts, share visions, set 
goals and targets, motivate members and shape the culture of the organization through their messages. A leader's word is an instrument for the exercise of power and a potent mechanism for motivating and persuading, by generating the force that drives followers' engagement with the leader's vision and goals (Mayfield et al., 2015; Venus et al., 2013). The perception that subordinates have about their supervisor's values, vision and leadership style is formed by the behaviors they observe, which include communicative ones. These communicative exchanges involve face-to-face or phone conversations, emails, meetings, written memos, etc., that occur during the performance of both routine and one-off tasks in everyday work. These exchanges not only fulfill the function of conveying and sharing information, ideas, opinions and feelings, but they also create mental frameworks and shape the reality that leaders will have to face together with their subordinates (Fairhurst, 2011).

Leadership communication partially explains organizational outcomes, in which good communication is positively related to performance (Clampitt and Downs, 1993; Goris, 2007; Pettit et al., 1997), organizational commitment (Mayfield and Mayfield, 2002; Postmes et al., 2001), job satisfaction (Hatfield and Huseman, 1982; Madlock, 2008; Miles et al., 1996), employee retention (Mayfield and Mayfield, 2007) and engagement (Thomas et al., 2009), as well as negatively related to absenteeism (Mayfield and Mayfield, 2009a). Effective leaders are, thus, commonly characterized by good communication skills. There is a wide literature regarding the desirable characteristics of the leader's communication. It may be that the leader is effective in interpersonal communication focusing mainly on the clarity to express ideas (Bambacas and Patrickson, 2008), the frequency (Abu Bakar et al., 2010; Bambacas and Patrickson, 2008; Kacmar et al., 2003), the openness and flexibility facilitating two-way interaction (Courtright et al., 1989; Yrle et al., 2002; Yukl and Fu, 1999) or the affirming and argumentativeness that generate trust regarding the leader's opinion (Infante and Gorden, 1989). Arguably, it is also important to note a leader's predisposition to communicate, a feature that is described in terms of empathy, friendliness, politeness and supportiveness, that contributes to a climate that facilitates interpersonal relationships with subordinates (Karasek et al., 1982; Michael, 2012). Likewise, transparency in the leader's communication contributes to the perception of integrity, which, in turn, is reflected in the worker's involvement and high performance (Vogelgesang et al., 2013).

Given the wide range of attributes commonly accepted in other studies, regarding the leader's communication and desired outcomes, this study corroborates the findings of other researchers in proposing the need for an integrated framework (de Vries et al., 2009; Fairhurst and Connaughton, 2014; Norton and Miller, 1975) to clarify the association between communication and leadership. This paper seeks to contribute to close the gap in understanding how the specific communicative behaviors of the leader reinforce or devitalize leadership and organizational commitment. This study's approach is communicational and builds upon other research to achieve its objective. Few integrated frameworks have been proposed to understand the communicative behaviors of an individual (de Vries et al., 2009; Gudykunst et al., 1996; Norton, 1978). The construct often used by researchers is the "communication style," defined as the personal way one verbally and paraverbally interacts to signal how literal meaning should be taken, interpreted, filtered, or understood (Norton, 1978). The model used in this study (de Vries et al., 2011; de Vries et al., 2010) identifies six observable dimensions in an LCS: expressiveness, preciseness, verbal aggressiveness, questioningness, emotionality and impression manipulativeness. Each one consists of four facets-level scales that can be associated with the traits that commonly accepted research acknowledges being desirable in a leader's communication. Following are the communicative behaviors of the leader according to the de Vries et al. (2009, 2010) model and upon which this study expounds.

Expressiveness. This dimension has the facets of talkativeness, conversational dominance, humor and informality. The leader shows a predisposition to talk, in a 
frequent and eloquent way, having difficulty to keep himself silent when around other people, and is usually the one who breaks the silence. The leader likes to express his/her ideas and lead the discussion, determining the topics discussed in a conversation. The leader acts in a casual an informal way, without creating unnecessary barriers, reducing the psychological distance with others, showing an open, non-conflictive attitude and good humor, with a suitable level of conversational adroitness toward all kinds of interlocutors.

Preciseness. It includes the facets of structuredness, thoughtfulness, substantiveness and conciseness. The leader shows accuracy in the communication of thoughts, through a logical and well-organized sequence of the different parts of the messages. This leader structures the message in a concise and pertinent manner, with substantive or significant data, and without dwelling on matters that are irrelevant to the purpose. This leader thinks carefully before saying something, choosing words with care and weighing the answers before expressing them. The messages are concise and involve important topics, avoiding trivial topics.

Verbal aggressiveness. This dimension includes the facets of anger, authoritarianism, derogatoriness and non-supportiveness. These leader's communicative behaviors include the open expression of displeasure or anger about issues or people. When the leader is angry, he takes it out on someone else and reacts irritably to people. The messages are expressed in a negative way. This leader tells people what to do, expects their obedience; and when asking for something, the tone of voice is demanding. The LCS manifests the trait of little respect for others' opinions, discourages dialog, humiliates, hurts feelings and makes others look like fools. The subordinates feel that the leader neither gives attention to them nor understands their problems or needs, and that he/she offers little support and treats people in a distant and cool way.

Questioningness. This dimension includes the facets of unconventionality, philosophicalness, inquisitiveness and argumentativeness. The leader likes to promote healthy debate and exchange of opinions, through the open discussion of new ideas, including wild or bizarre ones. This leader stimulates discussions about the future, engages in philosophical conversations and solicits different points of view. The leader usually uses questions to stimulate others to delve into a topic, seeking to challenge the team intellectually.

Emotionality. The dimension includes the facets of sentimentality, worrisomeness, tension and defensiveness. The leader manifests high levels of sentiment, including emotions and moods, when communicating during conversations. The leader tends to show concern, anxiety and stress about daily routine issues. As a mechanism for protecting against dissenting opinions or criticisms, the leader copes poorly with critical remarks.

Impression manipulativeness. This dimension includes ingratiation, charm, inscrutableness and concealingness. It refers to communicative behaviors related to the leader's concern of controlling or manipulating others' opinions. The leader expresses opinions different from what he/she really thinks, hiding the true way of thinking or information in order to appear better and gain acceptance from third parties, including boasting about ideas or achievements. He/she can show gentle, kind and courteous behavior, even with people or situations that he/she dislikes, in a polite and politically correct way.

Each one of the dimensions of the LCS is independent of the others and is measured on an independent scale. The leader could be high or low on some or on all of them. The dimensions are not a "type" or a primary communication style. The LCS integrates the six dimensions in a determinate amount, and the mix constitutes his or her personal and unique communication style (de Vries et al., 2010).

\section{Leadership and culture: the characteristics of outstanding leadership from a Latin American cultural perspective}

The GLOBE Project, still one of the most ambitious and comprehensive studies on culture, leadership and organizations available to date, shows that the desired leadership attributes LMX and
organizational
commitment

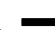




\section{LODJ}

Figure 1.

GLOBE Study: Scores for factors associated to outstanding leadership vary across cultures, and that effective managerial leadership requires an understanding of the effective managerial leadership required in each culture (House et al., 2004). The GLOBE study, thus, supports a Culturally Endorsed Implicit Leadership Theory providing evidence that societies and organizations share practices and values that define culture, leadership and organizational effectiveness (Dorfman et al., 2012).

Nevertheless, while some leadership behaviors are culturally sensitive, other attributes seem to be universally accepted characteristics that identify good leaders worldwide, such as value-based and charismatic/transformational leadership (Den Hartog et al., 1999; House et al., 2004; Dorfman et al., 2012) - despite some evidence on the contrary reported by Holten et al. (2018). Meanwhile, characteristics such as being solitary, non-cooperative, ruthless, non-explicit, irritable and dictatorial are considered universally not acceptable in a leader (Den Hartog et al., 1999).

Figure 1 presents the factors that contribute to or inhibit effective leadership, according to the GLOBE study, comparing the Latin American culture[1] with the average of the 62 countries included in the report. The Latin American cluster stands out for the great relevance attributed to charismatic, value-based and team-oriented leadership, while these societies seem to reject autonomous leaders who act independently and alone (GLOBE Foundation, n.d.).

The roots of different perceptions of what constitutes "good" leadership can be traced to equally different cultural values and practices (House et al., 2004; Minkov and Hofstede, 2011a, b). Latin American societies, such as Peru, are characterized by high power distance

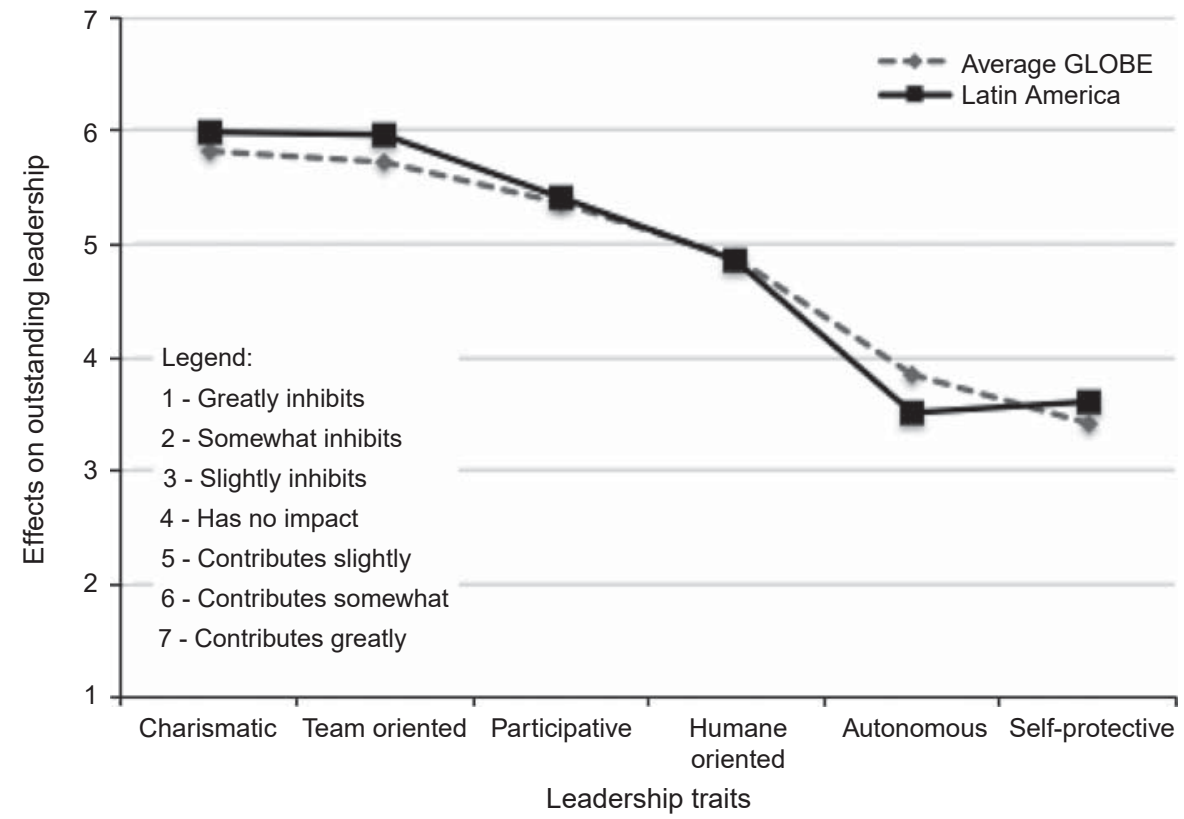

Notes: Data for Latin America aggregate ten countries: Argentina, Bolivia, Brazil, Colombia, Costa Rica, Ecuador, El Salvador, Guatemala, Mexico, and Venezuela. Meanwhile "average GLOBE" presents average information from the 60 studies included in the GLOBE 2004 study, across ten different culture groups: Eastern Europe, Latin America, Latin Europe, Confucian Asia, Nordic Europe, Anglo, Sub-Saharan Africa, Southern Asia, Germanic Europe and Middle East Source: GLOBE Foundation (n.d.) 
and collectivism (Hofstede Insights, n.d.). Collectivism is indeed associated to high-levels of team-oriented and charismatic leadership and low levels of leader autonomy. Meanwhile, a leader's behavior in societies characterized by high power distance is often autocratic and based on formal rules; effective leadership is associated to procedural, autonomous and performance-oriented leaders, rather than charismatic and value-based ones (House et al., 2004). This makes some of the GLOBE results for Latin America somewhat surprising from a theoretical standpoint. A plausible explanation may come from the striking gap that the GLOBE researchers found between cultural values (what the society believes should be) and current practices (what the society perceives it is) in Latin American societies (GLOBE Foundation, n.d.). In this context, transformational, charismatic and value-driven leaders can be seen as much-needed agents of change.

The GLOBE results, namely, the preference for charismatic and team-oriented leaders vs highly autonomous ones, reinforce the case for effective communication as a key tool for leaders to engage with their subordinates, share their vision and create cohesive working groups. This raises the question of what constitutes effective communication in this cultural context, and how it can stimulate healthy working relationship and employee commitment, which this paper addresses. Organizational environments generate spaces where the interaction between members reflect the cultural particularities of the individual and groups (Allen, 1995), and cultural patterns are reflected in communicative behaviors (Gudykunst et al., 1996). In this regards, this study ultimately explores the expected outcomes of the different dimensions of LCS.

\section{Research hypotheses}

\section{Effect of the leader's communication on AOC}

Employees often look upon leaders as the personification of the organization in their roles as representatives and spokespersons (Bambacas and Patrickson, 2008; Postmes et al., 2001). Numerous studies on organizational commitment reveal that committed employees perform better, they are more productive, they show greater engagement and appropriate corporate citizenship behaviors and record lower rates of absenteeism, intention to retire and turnover (Meyer et al., 2002).

Leadership communication partially explains organizational outcomes, whereby good communication is positively related to not only performance (Clampitt and Downs, 1993; Goris, 2007; Mayfield and Mayfield, 2010; Pettit et al., 1997) but also organizational commitment (Mayfield and Mayfield, 2002; Postmes et al., 2001).

The multidimensional model proposed by Allen and Meyer (1990), referred to as the Three Component Model of Commitment, has been widely used and accepted in research. Its three components are affective commitment, continuance commitment and normative commitment. Whereas the tree types are associated to lower turnover rates, the nature of the link differs: "Employees with strong affective commitment remain because they want to, those with strong continuance commitment remain because they need to, and those with strong normative commitment because they feel they ought to do so" (Allen and Meyer, 1990, p. 3). While continuance commitment is linked to the perceived costs of leaving the organization and normative commitment to obligations (either legal or ethical), affective commitment is based on desire, identification and personal engagement. It is thus unsurprising that previous research has found transformational leadership to be a much stronger antecedent of affective commitment that the other two components in Meyer and Allen's model (Meyer et al., 2002). Transformational leaders act as role models within the organization (Demirtas and Akdogan, 2015), create and communicate a vision (Herold et al., 2008) and increase followers' identification with the group and organization's values (Shamir et al., 1993). Rafferty and Griffin (2004) show that inspirational leader communication has a positive and significant effect on affective commitment. This is 
consistent with evidence showing that perceived organizational support is the strongest antecedent of affective commitment (Meyer et al., 2002). Organizations that provide a supportive work environment demonstrate their commitment to employees and most likely, may foster affective commitment among them (Eisenberger et al., 1986). Leaders play a key role in the way organizations interact with their employees, communicate organizational support and shape working environments; leaders are therefore instrumental in fostering affective commitment among their followers.

Meanwhile, previous research has been much less conclusive, both in terms of theoretical arguments and empirical evidence, regarding the relationship between leadership and communication and normative and continuance commitment (Meyer et al., 2002; Rafferty and Griffin, 2004). It is thus common that studies on the effects of leadership focus explicitly on AOC (e.g. Leroy et al., 2012; Demirtas and Akdogan, 2015).

Taking as a reference the generally accepted literature on leader's communication and organizational commitment, the dimensions of communication style may have an impact on such commitment. Subordinates see their leader as the organization's representative and spokesperson, expressly communicating the organization's mission and expectations of its employees, therefore influencing their emotional attachment to the organization. This study propounds the following proposition:

P1. An LCS is significantly related to the affective commitment of employees to the organization.

As this paper demonstrates, and backed by other rigorous studies, a leader's communication is a multidimensional construct based, hypothetically, on the expected effects of each of its dimensions on AOC. One may claim that expressiveness is favorably associated with AOC inasmuch as when leaders express themselves in an open, talkative and informal manner they create an atmosphere of openness, which employees may interpret as a positive feature of the organizational culture, increasing their engagement toward the organization. The predisposition of the leader to communicate, demonstrated through the frequency of the messages, expedites a better comprehension of the information, objectives and vision, as well as enforces trust among employees, all of which is essential for reinforcing commitment to the organization (Bambacas and Patrickson, 2008):

H1a. Expressiveness in the LCS is positively related to AOC.

Preciseness in the leader's communication helps employees to understand the organization's message (vision, targets, goals, policies), which may favor the message's proper interpretation, acceptance and assimilation. From the perspective of the studies on leader's integrity, transparent communication is related to the perception of integrity, and this in turn strengthens employee's commitment (Vogelgesang et al., 2013):

$H 1 b$. Preciseness in the LCS is positively related to AOC.

Conversely, verbal aggressiveness may not favor AOC. The behavior of supervisors with high verbal aggressiveness involves constant manifestations of anger, disproportionate annoyance when dealing with situations, teasing, ridiculing staff, becoming involved in a war of words and dismissing other people's opinions (de Vries et al., 2010; Infante et al., 1992). These situations constitute an attack on employees' need for self-expression and for reaffirming their sense of self (Infante and Gorden, 1985), leading to the creation of greater psychological distance, which may even influence upon employees' self-esteem and cause psychological damage (Becker et al., 2005; Deluga and Perry, 1991). These behaviors contravene employee's requirements in terms of AOC, as well as the support and perception of justice in management (Meyer and Smith, 2000), so we posit that:

H1c. Verbal aggressiveness in the LCS is negatively related to AOC. 
Questioningness is empirically a predictor variable of AOC insofar as when employees are involved in the definition of goals/targets, and they work toward shared goals, they become less competitive and more collaborative and create shared commitment and involvement (Mayer and Schoorman, 1992). Regarding emotionality in the leader's communication (expressions of feelings, concern, tension), this study contends that this dimension may be positively linked to affective commitment, as by showing emotions, a leader reveals more engagement with the mission, objectives and projects, which may be interpreted positively by subordinates and favor their affective commitment (Eisenberger et al., 2010):

H1d. Questioningness in the LCS is positively related to AOC.

H1e. Emotionality in the LCS is positively related to AOC.

Impression manipulativeness is expressed through communicative behaviors characterized by the lack of concordance between the message and the true thought, with the aim being to create positive perceptions in the opposing interlocutor (ingratiation), concealing one's true opinions and intentions, e.g., showing oneself to be charming, with sophisticated manners and inscrutability (de Vries et al., 2010). Subordinates would perceive these traits as inconsistent and lacking in transparency. The leader's behavioral integrity favours AOC (Leroy et al., 2012), whereby we contend that impression manipulativeness behaviors would be counterproductive, so the following hypothesis is proposed:

H1f. Impression manipulativeness in the LCS is negatively related to AOC.

The relationships hypothesized in $H 1 a-H 1 f$ above largely relate to leader attributes that are universally perceived as positive or negative, and are therefore not contingent on national culture (Den Hartog et al., 1999). Leaders showing verbal aggressiveness can be perceived as ruthless or irritable and high impression manipulativeness is related to leaders being selfserving, undependable, and untrustworthy. Meanwhile, expressiveness, preciseness, questioningness and emotionality are related to leaders being informed, inspirational, team integrators and performance oriented. Although these attributes are universally desirable (Den Hartog et al., 1999), they fit particularly well with cultures that value transformational leaders that are charismatic and team-oriented, as the GLOBE study shows it is the case for Latin American countries (GLOBE Foundation, n.d.).

\section{An LCS and LMX}

According to LMX theory, leadership is an associative relationship based on trust, respect and mutual obligation (Graen and Uhl-Bien, 1995). LMX theory suggests that leaders forge multiple and potentially heterogeneous one-to-one relationships with each of their followers. The relationship between leader and follower is created and maintained through day-to-day interactions in the execution of their roles (Fairhurst, 1993). Subordinates within the same working group often describe their supervisor in a different way: whereas some report interactions that are friendly, open, trusting, respectful and mutually supportive others describe relations characterized by low trust, strictly work-related, unfriendly, distant, confrontational and even aggressive. These differences give rise to what has been defined as high-quality, medium-quality and low-quality LMX relationships (Graen and Uhl-Bien, 1995).

High-quality LMX relationships are close and friendly, with followers acting as "trusted assistants," and performing tasks over and above their assigned duties, whereby a positive perception of the subordinate is expressed in high performance assessments. In contrast, the followers in low-quality LMX relationships assume passive roles, simply performing the duties set out in their job descriptions (Liden and Graen, 1980). The time, frequency and quality of contacts inform the creation and development of the LMX relationship. The quality of LMX may be related to communicative exchanges, whereby this theory provides 
a useful framework for investigating how the dimensions of the communication style are related to leadership.

Dansereau et al. (1975) recognize the communicative nature of LMX. Numerous studies on LMX and communication have shown the interaction between leader's communication and LMX. In high quality LMX relationships, the communication between leader and follower is defined by openness, trust, empathy and the leader's interest in the employee or follower (Fairhurst, 1993). Fix and Sias (2006) report that a person-center communication style in the supervisor contributes to higher-quality leader-member relationships. At the same line, Abu Bakar et al. (2010) propose that positive relationships communication, upward openness communication and job-relevant communication partially mediated the relation between LMX and group commitment. Regarding the frequency of communication contacts, Salvaggio and Kent (2016) found evidence of its positive effect on the relation between charisma and LMX. By contrast, communication with a low quality LMX is defined by communicative patterns that are cold, distant, antagonistic and confrontational, explained by a divergence of opinions, probable rivalry or the subordinate's communicative traits, such as communicative apprehension, shyness or a low predisposition to communicate. Based on the above reasoning, this study formulates the following general proposition:

P2. An LCS is significantly related to LMX.

Members of the social system of the organization perform roles to satisfy expectations of the other members about their responsibilities, and the communication of the expectations to the member is crucial (Katz and Kahn, 1978). From the constructionist perspective of followership (Uhl-Bien et al., 2014), leaders and followers co-create the leadership process through the interchanges that contribute to define identities and execute roles. LMX theory defines leadership structure as the pattern of leadership relationships among individuals in which leader and followers execute their role sets through the exchanges that take place in each of the episodes of the day-to day. On the base of the interchanges, the relationship is created, grows and facilitate the incremental influence necessary for the effective leadership (Graen and Uhl-Bien, 1995).

In the model of leadership making of LMX (Graen and Uhl-Bien, 1995), the process begins with a "stranger" phase, in which the leader and follower come together as strangers occupying interdependent organizational roles. The interactions occur on a formal bases-in essence, as an economic exchange, purely contractual: leaders provide followers only with what they need to perform, and followers perform only as required on their prescribed job. One of the parties makes an "offer" that must be communicated and accepted by the dyad to move on to the second stage of relationship development: the "acquaintance" phase. The social exchanges increase, and not all are contractual, but these exchanges are still limited. When the relationship grows to the next level, based on the day-to-day social exchange in the execution of their roles, the dyad goes into the "maturity" phase, in which the working relationship expands on reciprocations, giving each other with loyalty and support. The exchanges are not only behavioral but also emotional: mutual respect, trust and obligation. It is at this stage of maturity when the incremental influence and leadership between the members could grow to extremely high levels. Not all the dyads evolve at the same pace and some never rise the maturity level, but stay at the acquaintance or stranger stages. Interchanges are communicational behaviors, so it could be expected that the LCS influences on the evolution of the relationship and varies in the different stages of the LMX.

Because communication is the mechanism through which individuals interrelate, we propose that certain traits of the LCS can favor LMX while other aspects compromise it, to the extent that they contribute or not to the definition and fulfilment of the role expectations of the dyad during the different stages of the LMX relationship. Expressiveness may favor high-quality LMX relationships, because it involves open and frequent two-way 
communication behaviors that do not create unnecessary obstacles for interrelationships and are maintained in a friendly tone. Kacmar et al. (2003) report that LMX is more closely related to performance when individuals communicate frequently with their supervisor than when this communication is infrequent. Likewise, Bambacas and Patrickson (2008) report that the clear and frequent communication of messages, as well as the leader's active listening skills, contribute to an effective interpersonal relationship between supervisor and subordinate, which is a requirement for exercising leadership:

H2a. Expressiveness in the LCS is positively related to LMX.

The leader's skill in communicating in a concise, well-structured and pertinent manner helps to fulfill the function of clarifying tasks by reducing ambiguity and ensuring that subordinates understand their responsibilities, assigned tasks, targets and priorities, deadlines, and work standards, as well as understanding the rules, policies and procedures (Yukl and Fu, 1999). Subordinates expect their leaders to signal clearly the path to follow, to ensure that the group knows what to do, how to do it and the expected outcomes, all of which contribute to the leader's perceived effectiveness (House, 1996) and can favor the relationship:

$H 2 b$. Preciseness in the LCS is positively related to LMX.

Verbal aggressiveness has a negative effect on interpersonal relationships, being characterized by the frequent use of attacks, teasing, derogatory symbolic body language, threats, ridicule, bad mood, anger and a tendency to become involved in a war of words (Infante et al., 1992). It is one of the communicative traits with the biggest impact on satisfaction with a leader (Infante and Gorden, 1985). Subordinates view such behavior as a lack of support from their supervisor that creates a greater psychological distancing dismissing the creation and growth of LMX, and this behavior may even affect their self-esteem and cause psychological damage (Becker et al., 2005; Deluga and Perry, 1991):

H2c. Verbal aggressiveness in the leader's communication is negatively linked to LMX.

In the interchange of influences, leaders and followers contribute to fulfill both partners expectancies', clarify roles and establish identities (DeRue and Ashford, 2010; Hogg et al., 2012). From the perspective of role-based views of followership theory, followers could be in some way shapers of leader's actions, exert influence tactics and assume proactive behaviors as feedback-seeking, voice or taking charge behavior, that contribute to the co-creation of leadership (Uhl-Bien et al., 2014). In the same line, one of the pillars of transformational leadership is "intellectual stimulation." Leaders stimulate their followers to be innovative and creative, by questioning assumptions, reframing problems and approaching old situations in new ways: "new ideas and creative solutions to problems are solicited from followers, who are included in the process of addressing problems and finding solutions" (Bass et al., 2003, p. 208). LMX theory recognizes that leaders do not interact with all members of the group on an equal basis: higher quality LMX is characterized by greater levels of information exchange and employees have more opportunities for participation in the decision making process. In contrast, lower quality LMX relationships involve more formal supervision and fewer interactions, where the leader does not encourage the participation of employees with contributions of ideas or opinions (Graen and Uhl-Bien, 1995; Mueller and Lee, 2002). In this line of reasoning, we propose that:

H2d. Questioningness in the LCS is positively linked to LMX.

The behaviors associated with feelings (mood states and emotions) encompass the infinite range of human emotions. Behaviors involving positive sentimentalism lead to someone being perceived as excited, enthusiastic, active, euphoric, full of life and strong; whereas in the negative case the person could be seen as anxious, unsociable, hostile, worried, nervous, 
defensive, unkind and fearful. The generally accepted literature recognizes that leadership effectiveness is partly explained by the use leaders make of their emotions (Ashkanasy and Daus, 2002; Groves, 2006). Accordingly, a leader's affectivity, expressed through mood states and emotions, has been considered a significant ingredient of a charismatic leadership and decisive for its effectiveness by generating commitment among followers (Bono and Ilies, 2006). High quality LMX relationships are close and frequent, so the leader's emotional tone may have a significant impact on a follower's sentimentalism (Eberly and Fong, 2013), given that followers are influenced by their leader's mood states and emotions, which impact upon their relationship, performance and satisfaction (Sy et al., 2005). The following hypothesis is proposed:

H2e. Emotionality in the LCS is positively linked to LMX.

Regarding impression manipulativeness, such communicative behaviors may have a negative impact on LMX. Subordinates expect their leader to communicate openly and transparently, associating such behaviors with a perception of integrity that stimulates trust and their own engagement (Vogelgesang et al., 2013). These manipulative behaviors arise as instruments for wielding influence and power (Barbuto and Moss, 2006). A certain amount of impressionable manipulativeness occurs in situations in which a leader should behave in a "politically" appropriate manner, for example, courtesy, etiquette, and the necessary protocols in the negotiations with employees, peers, superiors or stakeholders. Nevertheless, ethics is a requirement that "lies at the very heart of leadership" (Ciulla, 1995), whereby behaviors involving manipulation, concealment and deception may be rejected by subordinates, as they are interpreted as a lack of transparency and even as dishonest.

$H 2 f$. Impression manipulativeness in the leader's communication is negatively linked to LMX.

It is legitimate to question whether the relationships above will hold equally strong in national cultures characterized by collectivism and high power distance - such as those in Latin America. We may argue that member's perceptions of LMX in vertical-collectivistic societies are shaped only by the leader's communicative behavior, but also by their own views of their role-based obligations (Rockstuhl et al., 2012). In other words, the leader's behavior is viewed as less important than roles and hierarchies in determining the quality of relationships. However, as we discussed in the background section above and as the GLOBE results for Latin America indicate societies that are highly hierarchical in terms of their cultural practices (what they are) may also be rather horizontal in terms of their cultural values (what they think they should be). They may also play outstanding value on leaders that are team-oriented and participative. Therefore, we can argue that the arguments leading to $H 2 a-H 2 f$ are likely to hold in the Peruvian cultural context.

\section{The impact of the LCS on AOC through LMX}

Drawing from the literature, one might expect that the LCS is a significant factor in the construction of LMX, and that the quality of the exchange contributes in turn to affective commitment to the organization. Some studies have found evidence on the relationship between an LCS and LMX (Fairhurst and Chandler, 1989; Fix and Sias, 2006; Geertshuis et al., 2015; Michael et al., 2005; Mueller and Lee, 2002), as well as between LMX and organizational commitment (Dulebohn et al., 2012; Eisenberger et al., 2010; Gerstner and Day, 1997; Wayne et al., 2002). The mediating role of LMX in the relationship between LCS and affective commitment toward the organization, however, remains largely unexplored. Our study seeks to help fill this gap.

It must be noted that affective commitment to the supervisor is a different construct to affective commitment to the organization (Stinglhamber and Vandenberghe, 2003), so some 
authors have suggested that LMX is related to outcomes that specifically benefit the supervisor rather than the organization (Vandenberghe et al., 2004). However, leaders are often perceived as an important proxy for the organization (Eisenberger et al., 1986): followers in high-quality relationships are, on average, more likely to experience positive affects toward the organization and feel committed to it (Dulebohn et al., 2012) - although there is substantial variability in the strength of this relationship (Eisenberger et al., 2010). We must not overlook that leaders act as organizational agents who try to encourage followers to commit to the organization (Wayne et al., 2002); they are more likely to succeed in high-quality relationships that foster empowerment (Liden et al., 2000) and trust among their followers.

We can thus posit that the interpersonal relationship between subordinate and supervisor may constitute a bridge toward the generation of commitment toward the organization. Moreover, previous evidence suggests that this link is largely independent of national culture. In a meta-analysis of correlates of LMX across 23 countries, Rockstuhl et al. (2012) find that the national context does not have a significant effect on the relationship between LMX and affective commitment:

P3. LMX mediates the relationship between an LCS and the affective commitment to the organization.

Therefore, following the arguments that posed in support of $P 1$ and $P 2$, we may contend that the dimensions of the LCS that are positively related to LMX, and by extension to AOC are expressiveness, preciseness, questioningness and emotionality. The dimensions verbal aggressiveness and impression manipulativeness would be negatively related to LMX and by extension to organizational commitment:

$H 3 a$. The positive relationship between expressiveness in the leader's communication and affective commitment is mediated by the LMX.

$H 3 b$. The positive relationship between preciseness in the leader's communication and affective commitment is mediated by the LMX.

$H 3 c$. The negative relationship between verbal aggressiveness in the leader's communication and affective commitment is mediated by the LMX.

$H 3 d$. The positive relationship between questioningness in the leader's communication and affective commitment is mediated by the LMX.

H3e. The positive relationship between emotionality in the leader's communication and affective commitment is mediated by the LMX.

$H 3 f$. The negative relationship between impression manipulativeness in the leader's communication and affective commitment is mediated by the LMX (Figure 2).

\section{Method}

\section{Sample}

The database was built through the participation of practitioners who were contacted during their time of studying graduate, executive education, professional and management development programmes or on-site corporate training courses at ESAN Graduate School of Business (Lima, Peru). The questionnaire was administered in eighteen classroom groups between March and July, 2017. The survey was administered on paper, lasting on average $30 \mathrm{~min}$. The questionnaire was completed voluntarily by 279 subjects. After discarding unusable or incomplete questionnaires, we obtained 253 valid responses.

\section{LMX and organizational commitment}




\section{LODJ}

Figure 2.

The research model

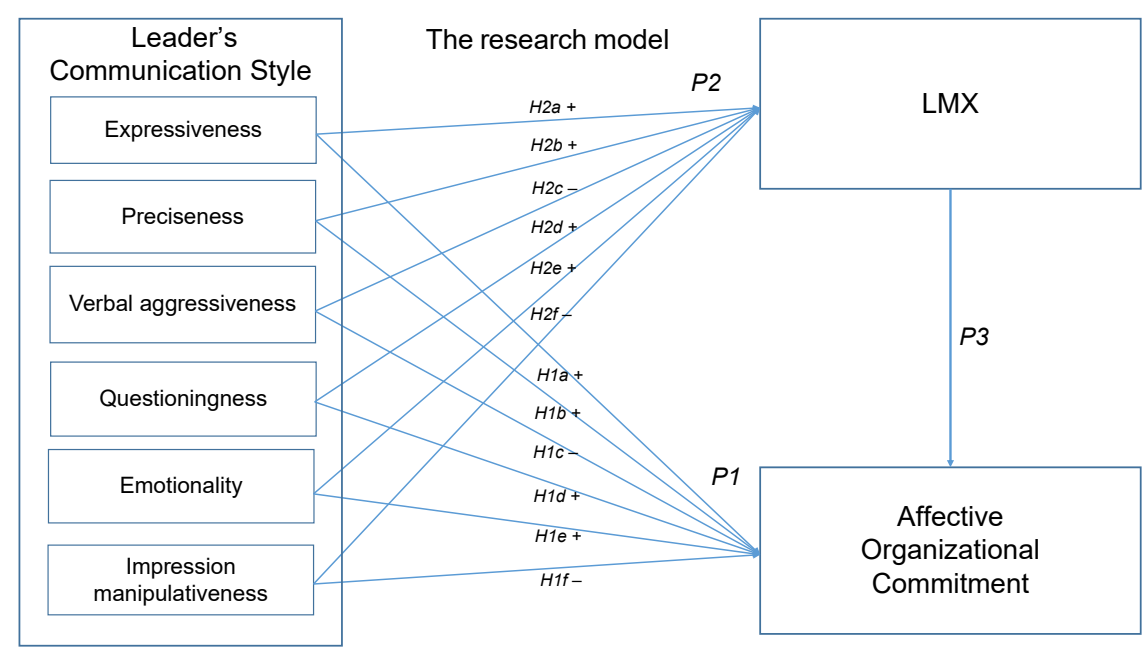

Student samples are adequate if they represent a population of interest (Peterson and Merunka, 2014). Moreover, our sampling technique allowed us to minimize biases potentially arising from missing data. The participants work in private companies (73 percent), government agencies (17.9 percent) or mixed public-private partnerships (6.6 percent). They are mostly male (64 percent), with an average age of 35 years, and a median of 34 . They all report having some professional experience, which in 99.3 percent of the cases is at least one year. Average experience is 10.8 years, with a median of 9.5. They are essentially Peruvian nationals (98 percent). Regarding the level of studies, 19.5 percent have technical or secondary level studies; 53.8 percent are university graduates and 26.7 percent have studied masters or higher education. About the nature or their jobs, 49.6 percent of the sample report working in technical positions, administrative assistant or analyst, and 46.9 percent hold managerial positions, such as supervisors, managers, or directors. Overall, they are a sample of mature students or professionals taking part in training programs; this type of sample has proved to be representative of wider populations in previous research (e.g. Jones and Sonner, 2001); sampling has been carefully designed to insure that participants comment on their own actual experience in the workplace, rather than provide hypothetical opinions. Moreover, they represent a wide range of practitioners and are not heavily concentrated in particular demographic groups or industries. Therefore, this study avoids the two most common pitfalls traditionally associated to conventional student samples (Bello et al., 2009). Table I summarizes the demographic characteristics of the sample in terms of frequencies.

\section{Measures}

The questionnaire was designed by adjusting the questions to be applied to the subordinates, in order to reduce the self-assessment bias on LCS. To achieve the objectives of the study, the study measures the employees' perception of their LCS, how they perceive the quality of the dyadic relationship (LMX), and their AOC at the same moment in time (Conway and Lance, 2010).

LCS was measured using the CSI by de Vries et al. (2011), consisting of 96 items organized into six domains, corresponding to the construct's six dimensions. The score was provided by a five-point Likert-type scale ranging from 1 (totally disagree) to 5 (totally agree). To mitigate order effects, the questions were randomly presented. LMX was measured using Graen and Uhl-Bien's (1995) instrument, with seven items on a five-point 


\begin{tabular}{|c|c|c|c|c|c|c|}
\hline & Freq. & $\%$ & & Freq. & $\%$ & $\begin{array}{l}\text { LMIX and } \\
\text { oroanizational }\end{array}$ \\
\hline $\begin{array}{l}\text { Age } \\
18-25 \\
26-35 \\
36-45 \\
45-55 \\
>55\end{array}$ & $\begin{array}{r}31 \\
139 \\
82 \\
19 \\
8\end{array}$ & $\begin{array}{r}11.1 \\
49.8 \\
29.4 \\
6.8 \\
2.9\end{array}$ & $\begin{array}{l}\text { Employer sector } \\
\text { Private sector } \\
\text { Public sector (government) } \\
\text { Social enterprise } \\
\text { Cooperative } \\
\text { Mixed (public private) } \\
\text { n/a }\end{array}$ & $\begin{array}{r}200 \\
49 \\
3 \\
4 \\
18 \\
5\end{array}$ & $\begin{array}{r}71.7 \\
17.6 \\
1.1 \\
1.4 \\
6.5 \\
1.8\end{array}$ & commitment \\
\hline $\begin{array}{l}\text { Gender } \\
\text { Woman } \\
\text { Man }\end{array}$ & $\begin{array}{l}103 \\
176\end{array}$ & $\begin{array}{l}36.9 \\
63.1\end{array}$ & $\begin{array}{l}\text { Employer nationality } \\
\text { Peruvian }\end{array}$ & 173 & 62.0 & \\
\hline $\begin{array}{l}\text { Nationality } \\
\text { Peruvian } \\
\text { Other }\end{array}$ & $\begin{array}{r}263 \\
16\end{array}$ & $\begin{array}{r}94.3 \\
5.7\end{array}$ & $\begin{array}{l}\text { Foreign } \\
\mathrm{n} / \mathrm{a} \\
\text { Workplace size }\end{array}$ & $\begin{array}{r}100 \\
6\end{array}$ & $\begin{array}{r}35.8 \\
2.2\end{array}$ & \\
\hline $\begin{array}{l}\text { Work experience (years) } \\
<5 \\
5-10 \\
11-20 \\
>20\end{array}$ & $\begin{array}{r}53 \\
112 \\
81 \\
33\end{array}$ & $\begin{array}{l}19.0 \\
40.1 \\
29.0 \\
11.8\end{array}$ & $\begin{array}{l}2-10 \\
11-100 \\
101-200 \\
>200 \\
\mathrm{n} / \mathrm{a}\end{array}$ & $\begin{array}{r}13 \\
51 \\
25 \\
181 \\
9\end{array}$ & $\begin{array}{r}4.7 \\
18.3 \\
9.0 \\
64.9 \\
3.2\end{array}$ & \\
\hline $\begin{array}{l}\text { Department } \\
\text { Admin, Accounting, Finance } \\
\text { Sales } \\
\text { Operations } \\
\text { R\&D } \\
\text { IT } \\
\text { HRM } \\
\text { Marketing } \\
\text { Other } \\
\text { n/a }\end{array}$ & $\begin{array}{l}67 \\
37 \\
33 \\
26 \\
26 \\
24 \\
13 \\
42 \\
11\end{array}$ & $\begin{array}{r}24.0 \\
13.3 \\
11.8 \\
9.3 \\
9.3 \\
8.6 \\
4.7 \\
15.1 \\
3.9\end{array}$ & & & & \\
\hline Source: Authors & & & & & & Sample demographics \\
\hline
\end{tabular}

Likert-type scale, where 1 indicates "totally disagree" and 5 means "totally agree." AOC was measured through two items from the scale by Meyer and Herscovitch (2001) using the performance approach. The answers were scored on a five-point Likert-type scale where 1 indicates "totally disagree" and 5 means "totally agree." The control variables considered were the age and gender of both subordinate and leader, as well as the time (in months) that respondents have been working under the supervision of their current leader.

\section{Procedures}

The quality of the data was verified by observing the mean and standard deviation for all the variables. The common method bias was measured by running the Harman single factor test (Podsakoff et al., 2003) with all the items, with 28 factors being extracted that explain over 68 percent of the total variance, with the first factor explaining close to 20 percent. A single factor was not obtained, and there was no single factor that explains most of the variance, so it may be posited that these two conditions reduce the possibility that the common-bias method may be a limitation in this study.

Multicollinearity was not a problem here, as the variance inflation factor (VIF) scores did not exceed 2.1 in any case. The data were processed using SPSS version 21 statistical software and PROCESS macros (version 2.16) (Hayes, 2013). The hypotheses were verified through multiple regression, and indirect effects were evaluated by means of Sobel tests with bootstrapping, 
which allowed for jointly testing the coefficient in the indirect path, namely the $\mathrm{a} \times \mathrm{b}$ product (Hayes, 2013; Preacher and Hayes, 2004, 2008). This approach extends the original causal steps methodology first proposed by Baron and Kenny (1986) for mediation analysis.

\section{Results}

Table II presents the mean, standard deviation and correlations. AOC is significantly correlated with four dimensions of the LCS and correlates with LMX. The mediator variable LMX correlates with all the dimensions of the LCS.

A first Model (Table III, Model 1) was used to examine the first set of hypotheses, whereas the model shows significant explanatory power, contrary to expectations, only preciseness shows to be significantly associated to commitment (total effect). Therefore, we accept $H 1 b$. There is no evidence supporting arguments claiming that other aforementioned dimensions of the communication style are related with affective commitment.

A second set of hypotheses were proposed with regard to the relationship between the dimensions of communication style and LMX (Table III, Model 2). Results show evidence supporting a close relationship between a subordinate's appraisal of the leader's communication and the quality of the inter-personal interaction between them. The regression coefficients indicate that four dimensions are significantly related with LMX. Expressiveness, preciseness, and questioningness show a positive relationship, while verbal aggressiveness records a negative one. These results provide evidence supporting $H 2 a-H 2 d$. Meanwhile, there is no evidence to show that emotionality $(H 2 e)$ and impression manipulativeness $(H 2 f)$ are significantly related with LMX, so these two hypotheses are not confirmed.

Our third proposition considered the role of LMX as a mediator between an LCS and AOC. The direct (vs total) effect of the dimensions of the LCS on affective commitment as their regression coefficients when controlling for the mediator variable (LMX) (Hayes, 2013; Preacher and Hayes, 2004, 2008) are shown in Model 3 (Table III). The model explains a significant percentage of the variance in affective commitment, whereas other organizational factors are obviously at play, this study demonstrates that the behavior of individual leaders and their interpersonal exchanges with their subordinates play indeed a relevant role on the subordinates' commitment. The results show (Table III, Model 3) that the variable preciseness records a significant coefficient and LMX is equally significant. The remaining dimensions of communication style do not show a significant direct effect on AOC.

The indirect effect is verified through the conditional process methodology propounded by Preacher and Hayes. This effect can be confirmed through bootstrapping and the Sobel test. The results obtained are shown in Table IV.

The dimensions expressiveness $(H 3 a)$, preciseness $(H 3 b)$, verbal aggressiveness $(H 3 c)$ and questioningness $(H 3 d)$ record significant results in both tests, thereby confirming the indirect effect on AOC through LMX. By contrast, the dimensions emotionality (H3e) and impression manipulativeness $(H 3 f)$ do not record significant results, so these hypotheses are rejected.

Some of the results, in particular the fact that we find significant indirect effects along with non-significant total effects for some independent variables, may come as a surprise to readers who are familiar to the causal steps methodology for mediation analysis developed by Baron and Kenny (1986). In this approach, a significant total effect is a necessary condition for claiming a mediated relationship. However, subsequent research has highlighted that total effects should not be used as "gatekeepers" for tests of mediation (Hayes, 2009; Shrout and Bolger, 2002). In particular, the causal steps approach involves multiple significance tests, and has shown low statistical power in the presence of finite samples and small, direct effects, resulting in very inflated Type I error rates (Fritz and MacKinnon, 2007). In this study, given the sample size and the non-significant direct effects, we rely on the bootstrap method (MacKinnon et al., 2004) to produce consistent confidence intervals - and hence significance levels - for testing the indirect effect. 


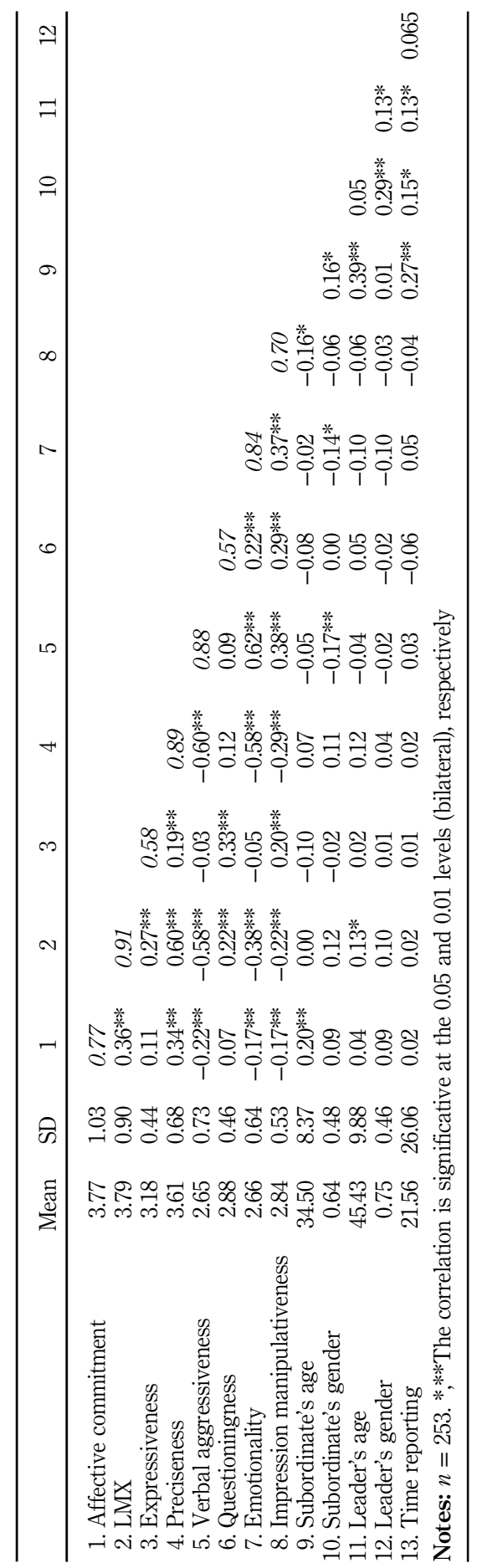




\section{LODJ}

\begin{tabular}{|c|c|c|c|c|c|c|}
\hline & \multicolumn{2}{|c|}{$\begin{array}{c}\text { Model } 1 \\
\text { Affective commitment } \\
\text { total effect }\end{array}$} & \multicolumn{2}{|c|}{ Model 2} & \multicolumn{2}{|c|}{$\begin{array}{c}\text { Model } 3 \\
\text { Affective commitment } \\
\text { direct effect }\end{array}$} \\
\hline & $\beta$ & SE & $\beta$ & SE & $\beta$ & SE \\
\hline 1. Intercept & 0.78 & 0.90 & $1.44^{*}$ & 0.60 & 0.33 & 0.90 \\
\hline 2. Subordinate's age & $0.03^{* * *}$ & 0.01 & -0.01 & 0.01 & $0.30 * * *$ & 0.01 \\
\hline 3. Subordinate's gender & 0.02 & 0.14 & 0.00 & 0.09 & 0.02 & 0.13 \\
\hline 4. Leader's age & -0.01 & 0.01 & 0.01 & 0.00 & -0.01 & 0.01 \\
\hline 5. Leader's gender & 0.20 & 0.14 & 0.14 & 0.09 & 0.16 & 0.14 \\
\hline 6. Time reporting & -0.002 & 0.00 & 0.00 & 0.00 & 0.00 & 0.00 \\
\hline 7. Expressiveness & 0.19 & 0.15 & $0.31 * *$ & 0.10 & 0.09 & 0.15 \\
\hline 8. Preciseness & $0.45^{* * * *}$ & 0.13 & $0.43^{* * * *}$ & 0.08 & $0.32 *$ & 0.13 \\
\hline 9. Verbal aggressiveness & -0.05 & 0.12 & $-0.51^{* * * *}$ & 0.08 & 0.11 & 0.12 \\
\hline 10. Questioningness & 0.11 & 0.153 & $0.31 * *$ & 0.10 & 0.01 & 0.15 \\
\hline 11. Emotionality & 0.10 & 0.14 & 0.11 & 0.09 & 0.06 & 0.14 \\
\hline 12. Impression manipulativeness & -0.18 & 0.13 & -0.13 & 0.09 & -0.14 & 0.13 \\
\hline 13. LMX & & & & & $0.31^{* * * *}$ & 0.09 \\
\hline Adjusted $R^{2}$ & 0.17 & & 0.52 & & 0.21 & \\
\hline$F$ for $R^{2}$ & $4.635^{* * * *}$ & & $23.476^{* * * *}$ & & $5.335^{* * *}$ & \\
\hline
\end{tabular}

Table III.

Multiple regression of the leader's communication style and LMX as predictors of affective organizational commitment

\begin{tabular}{lrrrrrrrr}
\hline & \multicolumn{4}{c}{ Bootstrapping } & \multicolumn{4}{c}{ Sobel test } \\
& Effect & Boot SE & Boot LLCI & Boot UCLI & Effect & SE & $z$ & $p$ \\
\hline Expressiveness & 0.098 & 0.047 & 0.028 & 0.217 & 0.981 & 0.045 & 2.204 & 0.028 \\
Preciseness & 0.133 & 0.054 & 0.050 & 0.265 & 0.133 & 0.049 & 2.736 & 0.006 \\
Verbal aggressiveness & -0.159 & 0.061 & -0.299 & -0.057 & -0.159 & 0.054 & -2.926 & 0.003 \\
Questioningness & 0.098 & 0.048 & 0.027 & 0.223 & 0.098 & 0.045 & 2.196 & 0.028 \\
Emotionality & 0.035 & 0.331 & -0.017 & 0.118 & 0.035 & 0.032 & 1.096 & 0.273 \\
Impression manipulativeness & -0.042 & 0.036 & -0.142 & 0.008 & -0.042 & 0.031 & -1.322 & 0.186
\end{tabular}

Table IV.

Indirect effect of leader's communication style on affective organizational commitment through LMX

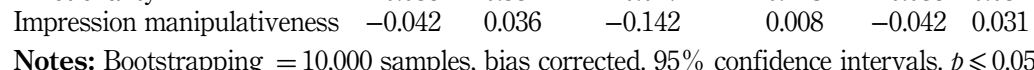

\section{Discussion}

From a conceptual perspective, this research contributes to a better understanding of communication style mechanisms that support leaders in building leadership relationships with their collaborators and enhance AOC. This is the first research made in a Peruvian organizational context on these issues. Over the past decade, Peru has been one of the region's fastest-growing economies, with an average growth rate 5.9 percent in a context of low inflation (averaging 2.9 percent) (World Bank, 2018). Much of the growth of the Peruvian economy is explained by an exogenous factor: the price of metals and not by endogenous factors. Peruvian leaders are challenged to take advantage of the window of opportunity generated by the price of metals to boost the economy and build endogenous growth factors. One of the factors that can contribute to growth is through leadership itself. Therefore, this research seeks to contribute to the strengthening of leadership through the tool of the leader's own communication style.

Previous research on the relationships between communication, leadership, LMX and commitment has focused mostly on Western horizontal-individualistic countries. However, as mentioned in the previous sections, an LCS is strongly associated with its context. It is known, from communication theory, that the sender must adapt his style of communication to the 
characteristics and needs of the receiver. Therefore, the leader must consciously make an effect of modulation or adaptation of the features of his/her style according to the needs of the receiver, his/her objectives and the context. Likewise, the implicit leadership theory (Phillips and Lord, 1986) explains that each individual has a mental pattern about leadership that is formed in his/her culture and they use this pattern to assess the behaviors of their supervisors. This study contributes to a better understanding of the effects of different communicative behaviors in a country characterized by vertical-collectivistic cultural practices.

We apply in this research the same inventory of communication styles that Bakker-Pieper and de Vries (2013) had previously used on a sample of Dutch employees. They reported four dimensions related to LMX: expressiveness $(\beta=0.35, p<0.01)$, preciseness $(\beta=0.28, p<0.01)$, emotionality $(\beta=0.32, p<0.01)$, and verbal aggressiveness $(\beta=-0.24, p<0.05)$. Meanwhile, we find expressiveness $(\beta=0.31, p<0.01)$, preciseness $(\beta=0.43, p<0.001)$, questioningness $(\beta=0.31, p<0.01)$, and verbal aggressiveness $(\beta=-0.51, p<0.001)$ to correlate with LMX. Therefore, we find similar results for four dimensions: three of them (expressiveness, preciseness and verbal aggressiveness) are significant and one (impression manipulativeness) is not significant. The differences that we find can indeed be linked to cultural patterns: members from vertical cultural settings (such as Peru) may perceive emotionality as unfit for a leader's role-based obligations, and therefore find it less desirable than members find in horizontal cultures (such as The Netherlands). Similarly, questioningness can be related to in-group collectivism and teamoriented and participative leadership (GLOBE Foundation, n.d.). In summary, our results, interpreted in the light of previous evidence from different cultural settings, are consistent with views of leadership - in our case, leadership communication - that combine some universal attributes with culture-specific ones (Den Hartog et al., 1999).

The findings show how Peruvian workers perceive their leaders through their communication, which aspects are the ones with greatest impact and how this is transferred to the AOC. The empirical evidence supports these study's three propositions:

P1. An LCS is significantly related to the affective commitment of employees to the organization.

P2. An LCS is significantly related to LMX.

P3. LMX mediates the relationship between an LCS and the affective commitment to the organization.

In regards to the first proposition, about the way LCS is related to employee's AOC, the results indicate that it is realised through one of the dimensions of LCS: preciseness. The quality of being precise, exact, concise skillful at composing messages, and doing so substantively without digressing or wasting time on irrelevant matters, showing expertise, is the characteristic of the leader's communication that makes a direct positive contribution to a subordinate's affective commitment to the organization (without the presence of LMX as mediator). Employees often look upon leaders as the personification of the organization in their roles as representatives and spokespersons (Bambacas and Patrickson, 2008; Postmes et al., 2001). In addition, the literature has established that leadership communication contributes to organizational commitment (Mayfield and Mayfield, 2002; Postmes et al., 2001). Preciseness has a distinct value that need to be foregrounded from the interpersonal exchanges between leaders and subordinates. The heavy use of information and communication technologies, work practices such as telecommuting and the geographical dispersion of teams may cause subordinates to feel overwhelmed with information, with rising barriers to personal relationships (Tapscott, 2015). Accurate and clear messages from superiors help subordinates to understand and value the relevance of their actions for the organization (Marques, 2010). Precision helps managers reduce ambiguity in 
communicating the organization's mission, vision and policies and envision change - messages that are usually defined as being non-structured and difficult to pin down (Yukl, 2012). By understanding the leader, subordinates understand the organization (Mayfield et al., 2015; Sullivan, 1988). In addition, this trait is associated with a transparent communication that arguably will enhance the perception of integrity, and in turn, strengthen an employee's commitment (Boies et al., 2015; Thomas et al., 2009). Based on the findings of this research, the proposition is made that preciseness could be used by leaders to consolidate the commitment to the organization, helping employees understand the organization's message (vision, targets, goals, policies), which may favor the message's proper interpretation, acceptance and assimilation.

Regarding the second proposition, this research has found empirical evidence of the association among four dimensions of the LCS - expressiveness, preciseness, verbal aggressiveness and questioningness - as to how it relates to the quality of LMX.

Verbal aggressiveness, perhaps not surprisingly is, from the subordinates' perspective, the trait that most affects the relationship with their leaders. Its detrimental effects, in terms of LMX, are comparatively stronger than the potential benefits realised from any of the other dimensions. These results are consistent with previous literature, which has shown an inverse relationship between an abusive supervision - a construct that is closely linked to perceived aggressiveness - and LMX (Xu et al., 2012). Recently, Sniderman et al. (2016) have shown that disconfirming managerial communication - a trait that typically involves some degree of verbal aggressiveness - triggers negative emotions among employees. In their model, LMX plays a moderating role, so that high-level LMX reduces the negative effects of disconfirming communication. Our findings show, however, that LMX cannot be just taken as an exogenous variable, being itself an outcome of communicative behaviors. In summary, this paper provides evidence suggesting a more complex set of causal linkages than previously considered in previous research.

The results for preciseness indicate that subordinates value a leader's ability to communicate in a manner that is precise, structured, concise, and pertinent regarding behaviors, such as loquacity or high participation, in two-way dialogues. Precision allows leaders to reduce any ambiguity over tasks, goals, targets and visions. They can generate trust through a better understanding of their messages, projecting effectiveness, expertise and professionalism, which favours leadership. In brief, preciseness minimizes the potential for misunderstandings and misalignments that may give rise to conflict and erode the quality of interpersonal exchanges.

Expressiveness and questioningness could contribute to LMX by generating closeness with the superior and the healthy exchange of opinions that allows subordinates to feel that they participate in the definition of their tasks and decision making that affect their work. This research did not find emotionality and impression manipulativeness to be significantly related to LMX. A plausible explanation for these unexpected findings may come from the contextual framework of this research. In societies with high power distance, such as Peru (Hofstede, 2016), supervisor-subordinate relationships in these types of societies are polarized and often emotional (Hofstede, 2001), which could explain why emotionality is not a significant factor in the construction of LMX, as it is taken for granted. Furthermore, whenever high power distance is present, the status symbols and privileges of those "at the top" are widely accepted. Their members seldom challenge leaders, and impression manipulativeness can be not only accepted, but also deemed necessary to uphold the system's privileges and prevalence.

The third proposition is that LMX mediates the relationship between an LCS and the affective commitment to the organization. This study proves that the four dimensions of an LCS - expressiveness, preciseness, verbal aggressiveness, and questioningness - show an indirect effect over AOC, providing evidence of the mediated role of LMX. This paper's 
findings confirm that the way a leader communicates influences the LMX relationship, and, in turn, an employee's affective commitment to the organization. The transition of the effect of communication on commitment is embodied through the construction of the supervisor-subordinate relationship, which is consistent with LMX theory. The relationship between the leader and the subordinate is created and maintained through communicative behaviors during the day-to-day interactions. The communicative nature of the LMX (Dansereau et al., 1975) could explain that the attributes in the leader's communication linked to LMX (expressiveness, preciseness, verbal aggressiveness, and questioningness) are interpreted by the employees as attributes of the organization itself, through the leader spokesperson and representative of the organization.

In that vein, leaders should be aware that their communications reinforce the workplace climate, encapsulate their leadership and contribute to organizational commitment. Although responsibility and workload exert pressure on leaders, they should strive to develop and uphold an open and informal style, with good humor, frequent and timely contacts, fostering the sharing of opinions, and respecting subordinates' right to take part in the definition of tasks, the search for new solutions and decision making. This communication style will reduce the psychological distance inherent to a hierarchical structure and create opportunities for continuous mutual feedback and support, and the leader will benefit through higher levels of information that will improve the quality of his/ her decisions. As demonstrated by Van Vuure et al. (2007), the satisfaction with a leader's communication contributes to AOC. Besides the benefits provided to both parties by good quality LMX relationships, the organization, in turn, will benefit from having employees that are committed to the corporate mission, vision and goals. They know, understand, accept and become involved, which will increase the chances of their efforts becoming aligned, thereby benefiting all the organization's members.

\section{Limitations and future lines of research}

The use of the CSI (de Vries et al., 2011) has been an essential tool as we have tried to advance theory in the context of the aforementioned thesis, in analyzing the organizational effect of different dimensions of leaders' communication. This instrument was originally drawn up for The Netherlands, and this paper employs it in a substantially different cultural context. The perceptions of communicative behaviors are demonstratively culture-specific, and some of our results suggest that future research may address the development of adapted models and measures that work well in different cultural environments. Future studies can explore the question whether the relationships we have identified would hold in societies with higher levels of individualism and lower power distance than Peru.

The subjects in our study are white-collar professionals, most of whom have completed higher education. The perceptions of communication, leadership and organizational commitment may differ across groups of employees occupying different positions and holding different qualifications. Therefore, our results cannot be readily generalized to the overall working population, and further research may identify other applications by studying samples representative of other strata in the working population.

\section{Managerial implications}

Communication styles can enhance affective commitment to the organization, because they project qualities of leadership that are highly valued today, as shown by the theories of charismatic and transformational leadership. A leader can use these communicative behaviors with a subordinate to forge a relationship of openness, trust and empathy; the subordinate receives support, sufficient and timely information, takes part in frequent dialogs and has the right to give an opinion to be respectively considered; all these are behaviors that, according to LMX theory, reinforce leadership (Graen and Uhl-Bien, 1995). 
The subordinates perceive that their supervisor represents values the subordinates find satisfactory, and generates a positive workplace climate, helping to bolster their AOC.

Leadership is an eminently social phenomenon (Burns, 1973) and the LMX theory propounded by Graen et al. has provided the framework for understanding that leadership is constructed in day-to-day work, through the communicative exchanges that take place during leaders' interactions over the course of their duties. Meanwhile, use of the multidimensional model first proposed by de Vries et al. has allowed us to obtain rich evidence on the association between the dimensions of communication style and the perceived quality of such human exchanges. The results we obtained are consistent with a view of organizations that favours increasingly horizontal, less hierarchical, more open and transparent interpersonal relationships in the workplace (Campbell et al., 2003; Mayfield and Mayfield, 2009b; Mueller and Lee, 2002).

\section{Conclusions}

The reported research has been conducted in the context of Peru, a country characterized by high power distance and collectivist. This study contributes to clarify that each feature of the LCS has a different impact on the perception of the subordinate. Thus, the leaders should be trained to understand this model and be able to make the necessary adjustments to obtain the desired leadership results. Four of the six dimensions of the leaders' communication style - expressiveness, preciseness, questioningness and verbal aggressiveness - are related to the quality of the LMX, and indirectly related to the AOC. The leader's ability to communicate with a style characterized by expressiveness, precision and questioning makes it easy to build high-quality LMX relationships for Peruvian employees. On the contrary, a communication style characterized by high levels of verbal aggressiveness will negatively affect subordinates, limiting the possibility of building high-quality LMX relationships.

The impact of the leader's communication on AOC is not only observed through the mediating effect of the LMX but also through the direct relationship between precision and organizational commitment. This finding implies that whatever the quality of the LMX relationship with the leader, the leader's ability to communicate in a concise, clear, structured manner, with a logical sequence appropriate to the topic, in a professional manner and without getting lost in irrelevant subjects, may impact directly the affective commitment of the subordinate to the organization. The subordinate can clearly understand directives, along with intangible values such as mission, vision, corporate objectives, which would lead to their acceptance and commitment.

The study of the leader's communication using an integrated model has facilitated the identification of specific traits, which can be modulated according to the context and the characteristics and needs of the subordinate. When training leaders in business schools and universities in Peru, teaching communication skills is considered of high importance, especially due to the current dynamics imposed by the rise of telecommunications and globalization. Our proposal can be expressed as follows: the communication style is the missing link between the theory of leadership and the exercise of leadership. We recommend incorporating a practical approach to the teaching of communication by linking communicative behaviours to the leadership model that is to be reinforced. It will help leaders establish the bridge between leadership theory and leadership exercise.

\section{Note}

1. The Latin American culture group is represented in the GLOBE 2004 report by the aggregation of ten countries: Brazil, Guatemala, Argentina, Ecuador, El Salvador, Colombia, Bolivia, Costa Rica, Venezuela and Mexico. Although Peru is not part of GLOBE 2004, it can safely be included within this culture group. 


\section{References}

LMX and

Abu Bakar, H., Dilbeck, K.E. and McCroskey, J.C. (2010), "Mediating role of supervisory communication practices on relations between leader-member exchange and perceived employee commitment to workgroup", Communication Monograbhs, Vol. 77 No. 4, pp. 637-656.

Allen, B.J. (1995), "Diversity and organizational communication", Lournal of Applied Communication Research, Vol. 23 No. 2, pp. 143-155.

Allen, N.J. and Meyer, J. (1990), "The measurement and antecedents of affective, continuance and normative commitment to the organization", Iournal of Occupational and Organizational Psychology, Vol. 63 No. 1, pp. 1-18.

Ashkanasy, N.M. and Daus, C.S. (2002), "Emotion in the workplace: the new challenge for managers", Academv of Management Executive, Vol. 16 No. 1, pp. 76-86.

Bakker-Pieper, A. and de Vries, R. (2013), "The incremental validity of communication styles over personality traits for leader outcomes", Human Performance, Vol. 26 No. 1, pp. 1-19.

Bambacas, M. and Patrickson, M. (2008), "Interpersonal communication skills that enhance organisational commitment", Journal of Communication Management, Vol. 12 No. 1, pp. 51-72.

Barbuto, J.E. and Moss, J.A. (2006), "Dispositional effects in intra-organizational influence tactics: a meta-analytic review", Journal of Leadership and Organizational Studies, Vol. 12 No. 3, pp. 30-48.

Baron, R.M. and Kenny, D.A. (1986), "The moderator-mediator variable distinction in social the moderator-mediator variable distinction in social psychological research: conceptual, strategic, and statistical considerations", Journal of Personality and Social Psychology, Vol. 51 No. 6, pp. 1173-1182.

Bass, B.M., Avolio, B.J., Jung, D.I. and Berson, Y. (2003), "Predicting unit performance by assessing transformational and transactional leadership", The Iournal of Applied Psychology, Vol. 88 No. 2, pp. 207-218.

Becker, J.A.H., Halbesleben, J.R.B. and O’Hair, H.D. (2005), "Defensive communication and burnout in the workplace: the mediating role of leader-member exchange", Communication Research Reports, Vol. 22 No. 2, pp. 143-150.

Bello, D., Leung, K., Radebaugh, L., Tung, R.L. and Van Witteloostuijn, A. (2009), "From the editors: student samples in international business research", Lournal of International Business Studies, Vol. 40 No. 3, pp. 361-364.

Boies, K., Fiset, J. and Gil, H. (2015), "Communication and trust are key: unlocking the relationship between leadership and team performance and creativity", The Leadership Quarterly, Vol. 26 No. 6, pp. 1080-1094.

Bono, J.E. and Ilies, R. (2006), “Charisma, positive emotions and mood contagion”, Leadership Quarterly, Vol. 17 No. 4, pp. 317-334.

Burns, T. (1973), “A structural theory of social exchange”, Acta Sociologica, Vol. 16 No. 3, pp. 188-208.

Campbell, K., White, C. and Johnson, D. (2003), "Leader-member relations as a function of rapport management", Journal of Business Communication, Vol. 40 No. 3, pp. 170-194.

Christensen, L.T. and Cornelissen, J. (2011), "Bridging corporate and organizational communication: review, development and a look to the future", Management Communication Quarterly, Vol. 25 No. 3, pp. 383-414.

Ciulla, J.B. (1995), "Leadership ethics: mapping the territory”, Business Ethics Quarterlv, Vol. 5 No. 1, pp. 5-28.

Clampitt, P. and Downs, C. (1993), "Employee perceptions of the relationship between communication and productivity: a field study", Lournal of Business Communication, Vol. 30 No. 1, pp. 5-28.

Conway, J.M. and Lance, C.E. (2010), "What reviewers should expect from authors regarding common method bias in organizational research", Journal of Business and Psychology, Vol. 25 No. 3, pp. 325-334.

Courtright, J., Fairhurst, G. and Rogers, L. (1989), "Interaction patterns in organic and mechanistic systems", Academy of Management Journal, Vol. 32 No. 4, pp. 773-802. 
Dansereau, F., Graen, G. and Haga, W.J. (1975), “A vertical dyad linkage approach to leadership within formal organizations. A longitudinal investigation of the role making process", Organizational Behavior and Human Performance, Vol. 13 No. 1, pp. 46-78.

de Vries, R.E., Bakker-Pieper, A. and Oostenveld, W. (2010), "Leadership = communication? The relations of leaders' communication styles with leadership styles, knowledge sharing and leadership outcomes", Journal of Business and Psychology, Vol. 25 No. 3, pp. 367-380.

de Vries, R.E., Bakker-Pieper, A., Konings, F.E. and Schouten, B. (2011), "The communication styles inventory (CSI): a six-dimensional behavioral model of communication styles and its relation with personality", Communication Research, Vol. 40 No. 4, pp. 506-532.

de Vries, R.E., Bakker-Pieper, A., Siberg, R.A., van Gameren, K. and Vlug, M. (2009), "The content and dimensionality of communication styles", Communication Research, Vol. 36 No. 2, pp. 178-206.

Deluga, R.J. and Perry, J.T. (1991), "The relationship of subordinate upward influencing behaviour, satisfaction and perceived superior effectiveness with leader-member exchanges", Journal of Occupational Psychology, Vol. 64 No. 3, pp. 239-252.

Demirtas, O. and Akdogan, A.A. (2015), "The effect of ethical leadership behavior on ethical climate, turnover intention, and affective commitment”, Journal of Business Ethics, Vol. 130 No. 1, pp. 59-67.

Den Hartog, D., House, R.J., Hanges, P.J. and Ruiz-Quintanilla, S.A. (1999), "Culture specific and crossculturally generalizable implicit leadership theories: are attributes of charismatic/ transformational leadership universally endorsed?", Leadership Quarterly, Vol. 10 No. 2, pp. 219-256.

DeRue, S. and Ashford, S. (2010), "Who will lead and who will follow? A social process of leadership identity construction in organizations", Academy of Management Journal, Vol. 35 No. 4, pp. 627-647.

Dorfman, P., Javidan, M., Hanges, P., Dastmalchian, A. and House, R. (2012), "GLOBE: a twenty year journey into the intriguing world of culture and leadership", Journal of World Business, Vol. 47 No. 4, pp. 504-518.

Drucker, P. (1988), “The coming of the new organization”, Harvard Business Review, Vol. 66 No. 1, pp. $45-53$.

Dulebohn, J.H., Bommer, W.H., Liden, R.C., Brouer, R.L. and Ferris, G.R. (2012), "A meta-analysis of antecedents and consequences of leader-member exchange: integrating the past with an eye toward the future", Journal of Management, Vol. 38 No. 6, pp. 1715-1759.

Eberly, M.B. and Fong, C.T. (2013), "Leading via the heart and mind: the roles of leader and follower emotions, attributions and interdependence", Leadership Quarterly, Vol. 24 No. 5, pp. 696-711.

Eisenberger, R., Huntington, R., Hutchison, S. and Sowa, D. (1986), "Perceived organizational support", Journal of Applied Psychology, Vol. 71 No. 3, pp. 500-507.

Eisenberger, R., Karagonlar, G., Stinglhamber, F., Neves, P., Becker, T.E., Gonzalez-Morales, M.G. and Steiger-Mueller, M. (2010), "Leader-member exchange and affective organizational commitment: the contribution of supervisor's organizational embodiment", Journal of Applied Psychology, Vol. 95 No. 6, pp. 1085-1103.

Fairhurst, G.T. (1993), "The leader-member exchange patterns of women leaders in industry: a discourse analysis", Communication Monographs, Vol. 60 No. 4, pp. 321-351.

Fairhurst, G.T. (2011), "Leadership and the power of framing”, Leader to Leader, Vol. 2011 No. 61, pp. 43-48.

Fairhurst, G.T. and Chandler, T.A. (1989), "Social structure in leader-member interaction", Communication Monographs, Vol. 56 No. 3, pp. 215-239.

Fairhurst, G.T. and Connaughton, S.L. (2014), "Leadership: a communicative perspective”, Leadership, Vol. 10 No. 1, pp. 7-35.

Fix, B. and Sias, P.M. (2006), "Person-centered communication, leader-member exchange, and employee job satisfaction”, Communication Research Reports, Vol. 23 No. 1, pp. 35-44.

Fritz, M.S. and MacKinnon, D.P. (2007), "Required sample size to detect the mediated effect", Psychological Science, Vol. 18 No. 3, pp. 233-239. 
Geertshuis, S.A., Morrison, R.L. and Cooper-Thomas, H.D. (2015), "It's not what you say, it's the way that you say it: the mediating effect of upward influencing communications on the relationship between leader-member exchange and performance ratings", International Journal of Business Communication, Vol. 52 No. 2, pp. 228-245.

Gerstner, C.R. and Day, D.V. (1997), "Meta-analytic review of leader-member exchange theory: correlates and construct issues", Journal of Applied Psychology, Vol. 82 No. 6, pp. 827-844.

GLOBE Foundation (n.d.), "Results - Latin America", available at: http:/globeproject.com/results/ clusters/latin-america?menu=cluster (accessed March 10, 2018).

Goris, J. (2007), "Effects of satisfaction with communication on the relationship between individual-job congruence and job performance/satisfaction", Journal of Management Development, Vol. 26 No. 8, pp. 737-752.

Graen, G.B. and Uhl-Bien, M. (1995), "Relationship-based approach to leadership: development of leader-member-exchange (LMX) theory of leadership over 25 years: applying a multi-level multidomain perspective", Leadership Quarterly, Vol. 6 No. 2, pp. 219-247.

Groves, K.S. (2006), "Leader emotional expressivity, visionary leadership, and organizational change", Leadership and Organization Development Journal, Vol. 27 No. 7, pp. 566-583.

Gudykunst, W., Yoon, Y. and Nishida, T. (1987), "The influence of individualism-collectivism on perceptions of communication in ingroup and outgroup relationships", Communication Monographs, Vol. 54 No. 3, pp. 295-306.

Gudykunst, W., Matsumoto, Y., Ting-Toomey, S., Nishida, T., Kim, K. and Heyman, S. (1996), "The influence of cultural individualism-collectivism, self construals, and individual values on communication styles across cultures", Human Communication Research, Vol. 22 No. 4, pp. 510-543.

Hamlin, R.G. (2004), "In support of universalistic models of managerial and leadership effectiveness: implications for HRD research and practice", Human Resource Development Quarterly, Vol. 15 No. 2, pp. 189-215.

Hammer, M., Gudykunst, W. and Wiseman, R. (1978), "Dimensions of intercultural effectiveness: an exploratory study", International Journal of Intercultural Relations, Vol. 2 No. 4, pp. 382-393.

Hatfield, J. and Huseman, R. (1982), "Perceptual congruence about communication as related to satisfaction: moderating effects of individual characteristics", Academy of Management Journal, Vol. 25 No. 2, pp. 349-358.

Hayes, A.F. (2009), "Beyond baron and kenny: statistical mediation analysis in the new millennium", Communication Monographs, Vol. 76 No. 4, pp. 408-420.

Hayes, A.F. (2013), Introduction to Mediation, Moderation, and Conditional Process Analysis: A Regression-Based Approach, Guilford Press, New York, NY.

Herold, D., Fedor, D., Caldwell, S. and Liu, Y. (2008), "The effects of transformational and change leadership on employees' commitment to a change: a multilevel study", Journal of Applied Psychology, Vol. 93 No. 2, pp. 346-357.

Hofstede, G. (2001), Culture's Consequences: Comparing Values, Behaviors, Institutions and Organizations Across Nations, 2nd ed., Sage Publications, Thousand Oaks, CA.

Hofstede, G. (2016), "Peru”, available at: https://geert-hofstede.com/peru.html (accessed March 27, 2017).

Hofstede Insights (n.d.), "Country comparison - Peru”, available at: www.hofstede-insights.com/ country-comparison/peru/ (accessed March 10, 2018).

Hogg, M., van Knippenbeg, D. and Rast, D. III (2012), "The social identity theory of leadership: theoretical origins, research findings, and conceptual developments", European Review of Social Psychology, Vol. 23 No. 1, pp. 258-304.

Holten, A., Bøllingtoft, A., Carneiro, I. and Borg, V. (2018), “A within-country study of leadership perceptions and outcomes across native and immigrant employees: questioning the universality of transformational leadership", Journal of Management and Organization, Vol. 24 No. 1, pp. 145-162. 
House, R.J. (1996), "Path-goal theory of leadership: lessons, legacy, and a reformulated theory", Leadership Quarterly, Vol. 7 No. 3, pp. 323-352.

House, R.J., Wright, N. and Aditya, R.N. (1997), "Cross-cultural research on organizational leadership: a critical analysis and a proposed theory", in Earley, P.C. and Erez, M. (Eds), New Perspectives on International/Organizational Psychology, New Lexington, San Francisco, CA, pp. 535-625.

House, R.J., Hanges, P.J., Javidan, M., Dorfman, P.W. and Gupta, V. (2004), Culture, Leadership, and Organizations. The GLOBE Study of 62 Societies, Sage Publications, Thousand Oaks, CA.

Infante, D.A. and Gorden, W.I. (1985), "Superiors' argumentativeness and verbal aggressiveness as predictors of subordinates' satisfaction”, Human Communication Research, Vol. 12 No. 1, pp. 117-125.

Infante, D.A. and Gorden, W.I. (1989), "Argumentativeness and affirming communicator style as predictors of satisfaction/disatisfaction with subordinates", Communication Quarterly, Vol. 37 No. 2, pp. 81-90.

Infante, D.A., Riddle, B.L., Horvath, C.L. and Tumlin, S.A. (1992), "Verbal aggressiveness: messages and reasons", Communication Quarterly, Vol. 40 No. 2, pp. 116-126.

Jones, W.L. and Sonner, B.S. (2001), "Just say no to traditional student samples", Journal of Advertising Research, Vol. 41 No. 5, pp. 63-71.

Kacmar, K.M., Witt, L.A., Zivnuska, S. and Gully, S.M. (2003), "The interactive effect of leader-member exchange and communication frequency on performance ratings", The Journal of Applied Psychology, Vol. 88 No. 4, pp. 764-772.

Karasek, R.A., Triantis, K.P. and Chaudhry, S.S. (1982), "Coworker and supervisor support as moderators of associations between task characteristics and mental strain", Journal of Occupational Behaviour, Vol. 3 No. 2, pp. 181-200.

Katz, D. and Kahn, R. (1978), The Social Psychology of Organizations, Vol. 2, Wiley, New York, NY, p. 528.

Leroy, H., Palanski, M.E. and Simons, T. (2012), "Authentic leadership and behavioral integrity as drivers of follower commitment and performance", Journal of Business Ethics, Vol. 107 No. 3, pp. 255-264.

Liden, R.C. and Graen, G. (1980), "Generalizability of the vertical dyad linkage model of leadership", Academy of Management Journal, Vol. 23 No. 3, pp. 451-465.

Liden, R.C., Wayne, S.J. and Sparrowe, R.T. (2000), "An examination of the mediating role of psychological empowerment on the relations between the job, interpersonal relationships, and work outcomes", Journal of Applied Psychology, Vol. 85 No. 3, pp. 407-416.

MacKinnon, D.P., Lockwood, C.M. and Williams, J. (2004), "Confidence limits for the indirect effect: distribution of the product and resampling methods", Multivariate Behavioral Research, Vol. 39 No. 1, pp. 99-128.

Madlock, P.E. (2008), "The link between leadership style, communicator competence, and employee satisfaction”, Journal of Business Communication, Vol. 45 No. 1, pp. 61-78.

Marques, J.F. (2010), "Enhancing the quality of organizational communication", Journal of Communication Management, Vol. 14 No. 1, pp. 47-58.

Mayer, R.C. and Schoorman, F.D. (1992), "Predicting participation and production outcomes through a two-dimensional model of organizational commitment", Academy of Management Journal, Vol. 35 No. 3, pp. 671-684.

Mayfield, J. and Mayfield, M. (2002), "Leader communication strategies critical paths to improving employee commitment", American Business Review, Vol. 20 No. 2, pp. 89-94.

Mayfield, J. and Mayfield, M. (2007), "The effects of leader communication on a worker's intent to stay: an investigation using structural equation modeling", Human Performance, Vol. 20 No. 2, pp. 85-102.

Mayfield, J. and Mayfield, M. (2009a), "The role of leader motivating language in employee absenteeism”, Journal of Business Communication, Vol. 46 No. 4, pp. 455-479. 
Mayfield, M. and Mayfield, J. (2009b), "The role of leader-follower relationships in leader communication: a test using the LMX and motivating language models", The Journal of Business Inquiry, Vol. 8 No. 1, pp. 65-82.

Mayfield, J. and Mayfield, M. (2010), "Leader-level influence on motivating language: a two-level investigation on worker performance and job satisfaction”, An International Business Journal, Vol. 20 No. 5, pp. 407-422.

Mayfield, J., Mayfield, M. and Sharbrough, W.C. III (2015), "Strategic vision and values in top leaders' communications: motivating language at a higher level", International Journal of Business Communication, Vol. 52 No. 1, pp. 97-121.

Meyer, J.P. and Herscovitch, L. (2001), "Commitment in the workplace. Toward a general model", Human Resource Management Review, Vol. 11 No. 3, pp. 299-326.

Meyer, J.P. and Smith, C.A. (2000), "HRM practices and organizational commitment: test of a mediation model", Canadian Journal of Administrative Sciences, Vol. 17 No. 4, pp. 319-331.

Meyer, J.P., Stanley, D.J., Herscovitch, L. and Topolnytsky, L. (2002), "Affective, continuance, and normative commitment to the organization: a meta-analysis of antecedents, correlates, and consequences", Journal of Vocational Behavior, Vol. 61, pp. 20-52.

Michael, D. (2012), "Supportive supervisor communication as an intervening influence in the relationship between LMX and employee job satisfaction, turnover intentions, and performance", Journal of Behavioral Studies in Business, Vol. 5, pp. 1-28.

Michael, D.F., Harris, S.G., Giles, W.F. and Feild, H.S. (2005), "The influence of supportive supervisor communication on LMX and performance: the test of a theoretical model", Academy of Management Annual Meeting Proceedings, Vol. 1, pp. F1-F6.

Miles, E., Patrick, S. and King, W. (1996), "Job level as a systemic variable in predicting the relationship between supervisory communication and job satisfaction", Journal of Occupational and Organizational Psychology, Vol. 69 No. 3, pp. 277-292.

Minkov, M. and Hofstede, G. (2011a), "Is national culture a meaningful concept?: Cultural values delineate homogeneous national clusters of in-country regions", Cross-Cultural Research, Vol. 46 No. 2, pp. 133-159.

Minkov, M. and Hofstede, G. (2011b), "The evolution of Hofstede's doctrine”, Cross Cultural Management: An International Journal, Vol. 18 No. 1, pp. 10-20.

Mueller, B.H. and Lee, J. (2002), "Leader-member exchange and organizational communication satisfaction in multiple contexts", Journal of Business Communication, Vol. 39 No. 2, pp. 220-244.

Norton, R.W. (1978), "Foundation of a communicator style construct", Human Communication Research, Vol. 40 No. 2, pp. 99-112.

Norton, R.W. and Miller, L.D. (1975), "Dyadic perception of communication style", Communication Research, Vol. 2 No. 1, pp. 50-67.

Peterson, R.A. and Merunka, D.R. (2014), "Convenience samples of college students and research reproducibility”, Journal of Business Research, Vol. 67 No. 5, pp. 1035-1041.

Pettit, J., Goris, J. and Vaught, B. (1997), "An examination of organizational communication as a moderator of relationship between job performance and job satisfaction", Journal of Business Communication, Vol. 34 No. 1, pp. 81-98.

Phillips, J.S. and Lord, R.G. (1986), "Notes of the practical and theoretical consequences of implicit leadership theories for the future of leadership measurement", Journal of Management, Vol. 12 No. 1, pp. 31-41.

Phillips, N., Lawrence, T. and Hardy, C. (2004), "Discourse and institutions", Academy of Management Review, Vol. 29 No. 4, pp. 636-652.

Podsakoff, P.M., MacKenzie, S.B., Lee, J.Y. and Podsakoff, N.P. (2003), "Common method biases in behavioral research: a critical review of the literature and recommended remedies", The Journal of Applied Psychology, Vol. 88 No. 5, pp. 879-903. 
Postmes, T., Tanis, M. and de Wit, B. (2001), "Communication and commitment in organizations: a social identity approach”, Group Processes Intergroup Relations, Vol. 4 No. 3, pp. 227-246.

Preacher, K.J. and Hayes, A.F. (2004), "SPSS and SAS procedures for estimating indirect effects in simple mediation models", Behavior Research Methods, Instruments, and Computers, Vol. 36 No. 4, pp. 717-731.

Preacher, K.J. and Hayes, A.F. (2008), "Asymptotic and resampling strategies for assessing and comparing indirect effects in multiple mediator models", Behavior Research Methods, Vol. 40 No. 3, pp. 879-891.

Rafferty, A.E. and Griffin, M.A. (2004), "Dimensions of transformational leadership: conceptual and empirical extensions", The Leadership Quarterly, Vol. 15 No. 3, pp. 329-354.

Rockstuhl, T., Dulebohn, S., Ang, S. and Shore, L. (2012), "Leader-member exchange (LMX) and culture: a meta-analysis of correlates of LMX across 23 countries", Journal of Applied Psychology, Vol. 97 No. 6, pp. 1097-1130.

Salvaggio, T. and Kent, T.W. (2016), "Examining the relationship between charismatic leadership and the lower-order factors of LMX", Leadership and Organization Development Journal, Vol. 37 No. 8, pp. 1223-1237.

Shamir, B., House, R. and Arthur, M. (1993), "The motivational effects of charismatic leadership: a selfconcept based theory", Organization Science, Vol. 4 No. 4, pp. 577-594.

Shrout, P.E. and Bolger, N. (2002), "Mediation in experimental and nonexperimental studies: new procedures and recommendations", Psychological Methods, Vol. 7 No. 4, pp. 422-445.

Sniderman, P., Fenton-O'creevy, M. and Searle, R. (2016), "Effects of managerial communication as moderated by LMX and trait NA", Journal of Managerial Psychology, Vol. 31 No. 6, pp. 1074-1090.

Stinglhamber, F. and Vandenberghe, C. (2003), "Organizations and supervisors as sources of support and targets of commitment: a longitudinal study", Journal of Organizational Behavior, Vol. 24 No. 3, pp. 251-270.

Sullivan, J.J. (1988), "Three roles of language in motivation theory”, Academy of Management Review, Vol. 13 No. 1, pp. 104-115.

Sy, T., Côté, S. and Saavedra, R. (2005), "The contagious leader: impact of the leader's mood on the mood of group members, group affective tone, and group processes", Journal of Applied Psychology, Vol. 90 No. 2, pp. 295-305.

Tapscott, D. (2015), The Digital Economy: Rethinking Promise and Peril in the Age of Networked Intelligence, McGraw Hill, New York, NY.

Taylor, J.R. (2011), “Organization as an (imbricated) configuring of transactions”, Organization Studies, Vol. 32 No. 9, pp. 1273-1294.

Thomas, G., Zolin, R. and Hartman, J. (2009), "The central role of communication in developing trust and its effect on employee involvement", Journal of Business Communication, Vol. 46 No. 3, pp. 27-310.

Uhl-Bien, M., Riggio, R., Lowe, K. and Carsten, M. (2014), "Followership theory: a review and research agenda", The Leadership Quarterly, Vol. 25 No. 1, pp. 83-104.

Van Vuure, M., de Jong, M. and Seydel, E. (2007), "Direct and indirect effects of supervisor communication on organizational commitment", Corporate Communications: An International Journal, Vol. 12 No. 2, pp. 116-128.

Vandenberghe, C., Bentein, K. and Stinglhamber, F. (2004), "Affective commitment to the organization, supervisor, and work group: antecedents and outcomes", Journal of Vocational Behavior, Vol. 64 No. 1, pp. 47-71.

Venus, M., Stam, D. and van Knippenberg, D. (2013), "Leader emotion as a catalyst of effective leader communication of visions, value-laden messages, and goals", Organizational Behavior and Human Decision Processes, Vol. 122 No. 1, pp. 53-68. 
Vogelgesang, G.R., Leroy, H. and Avolio, B.J. (2013), "The mediating effects of leader integrity with transparency in communication and work engagement/performance", Leadership Quarterly, Vol. 24 No. 3, pp. 405-413.

Wayne, S.J., Shore, L.M., Bommer, W.H. and Tetrick, L.E. (2002), "The role of fair treatment and rewards in perceptions of organizational support and leader-member exchange", Journal of Applied Psychology, Vol. 87 No. 3, pp. 590-598.

World Bank (2018), "Peru economy", available at: www.worldbank.org/en/country/peru (accessed July 22, 2018).

Xu, E., Huang, X., Lam, C.K. and Miao, Q. (2012), "Abusive supervision and work behaviors: the mediating role of LMX”, Journal of Organizational Behavior, Vol. 33 No. 4, pp. 531-543.

Yrle, A.C., Hartmann, S.J. and Galle, W. (2002), "An investigation of relationships between communication style and leader-member exchange", Journal of Communication Management, Vol. 6 No. 3, pp. 257-268.

Yukl, G. (2012), "Effective leadership behavior: what we know and what questions need more attention", Academy of Management Perspectives, Vol. 26 No. 4, pp. 66-85.

Yukl, G. and Fu, P.P. (1999), "Determinants of delegation and consultation by managers", Journal of Organizational Behavior, Vol. 20 No. 2, pp. 219-232.

\section{Further reading}

House, R., Javidan, M., Hanges, P. and Dorfman, P. (2002), "Understanding cultures and implicit leadership theories across the globe: an introduction to project GLOBE", Journal of World Business, Vol. 37 No. 1, pp. 3-10.

\footnotetext{
About the authors

Ofelia Brown is Part-Time Professor at ESAN School of Business, ESAN University (Perú), Senior Executive, Consultant and Lecturer for governmental bureaus and private companies. Her teaching and research focus on organizational communication, leadership, change management and interculturality. Ofelia Brown is the corresponding author and can be contacted at: obrown@esan.edu.pe

Carmen Paz-Aparicio is Assistant Professor at Universidad Carlos III de Madrid (Spain). Before joining this university she was Visiting Assistant Professor at the College of Charleston, SC (USA). Her teaching and research interests focuses mainly on cross-cultural management, expatriation, offshoring and leadership always from an international perspective.

Antonio J. Revilla is Senior Lecturer at Bath Business School (UK). His previous research has focused mainly on innovation management, corporate entrepreneurship and competitive dynamics. He has published his works in Family Business Review, Technovation, Strategic Organization, Journal of Business Research and Industry and Innovation, among other journals.
} LMX and
organizational
commitment 